Table Concentrations of potassium in serum and plasma compared with that of plasma from whole blood collected into Concord Pulsator syringes

\begin{tabular}{lllll}
\hline Subject & Serum (mmol/l) & Plasma (mmol/l) & $\begin{array}{l}\text { Correctly primed } \\
\text { syringe (mmolll) }\end{array}$ & $\begin{array}{l}\text { Incorrectly primed } \\
\text { syringe (mmol/l) }\end{array}$ \\
\hline 1 & 3.8 & 3.6 & 3.4 & 2.9 \\
2 & 4.3 & 4.1 & 3.8 & 3.2 \\
3 & 4.5 & 4.2 & 4.0 & 3.4 \\
4 & 4.2 & 4.9 & 3.7 & 3.7 \\
5 & 4.2 & 4.4 & 3.6 \\
\hline
\end{tabular}

\section{Dangerous hyperkalaemia after analysis of arterial blood sample}

Despite the known hazards of measuring electrolytes in heparinised arterial blood samples taken for blood gas analysis, ${ }^{1-3}$ we report a case of a patient whose arterial sample was used for measurement of electrolytes which led to incorrect and potentially dangerous treatment being given. We also report the use of the same commercially available arterial blood sampling syringe on the measurement of electrolytes in samples taken from five healthy subjects.

An arterial blood sample was collected in the coronary care unit from a 74 year old man with acute left ventricular failure using a Concord Pulsator syringe (Concord Laboratories Ltd, Folkestone, Kent). Blood gas and electrolyte analyses requested on this sample gave the following results: $\mathrm{pH} \mathrm{7.06}$, $\mathrm{pO}_{2} 71 \mathrm{~mm} \mathrm{Hg}, \mathrm{pCO}_{2} 73 \mathrm{~mm} \mathrm{Hg}$, base excess -12 , potassium concentration $2.5 \mathrm{mmol} / \mathrm{l}$. The patient was given $60 \mathrm{mmol}$ of potassium over two hours by infusion in $500 \mathrm{ml}$ of $5 \%$ dextrose. Eight hours later a further blood sample was collected. Analysis of this sample (SMAC 1, Technicon, Tarrytown, New York) gave a serum potassium concentration of $6.5 \mathrm{mmol} / 1$ which was confirmed by a repeat sample. There had been no deterioration in the patient's renal function since admission.

Subsequently, venous blood samples were also collected from five healthy subjects using Concord Pulsator syringes. One syringe had been correctly primed by expulsion of heparin diluent. The heparin diluent was not expelled from the other. Venous blood was also collected into a plain glass tube and into a lithium heparin tube. Potassium concentrations were measured in the serum or plasma by indirect ion selective electrode (SMAC 1, Technicon, Tarrytown, New York). The table shows the results. Compared with serum, there was an apparent fall in potassium concentration of up to $0.5 \mathrm{mmol} / 1$ when the syringe had been correctly primed in all samples but one. When the heparin diluent had not been expelled a fall in potassium concentration of up to $1.1 \mathrm{mmol} / 1$ occurred. A smaller but similar apparent fall in potassium concentration occurred on comparison with plasma samples. Heparin interference in the measurement of this patient's potassium concentration was unlikely to have occurred as the heparin concentration in the incorrectly primed syringe (about $140 \mathrm{U} / \mathrm{mL}$ ), would not have been high enough to interfere in ion selective electrode measurement. ${ }^{2}$

The potassium concentrations in the samples from the healthy subjects indicated that the patient's initially low potassium concentration was due to failure to expel the heparin diluent from the syringe. It is clear, however, that even when the syringe was used correctly a considerable fall in measured potassium concentration could still occur.

WD NEITHERCUT JM ORRELL

Department of Pathological Biochemistry, Western Infirmary, Glasgow G11 6NT.

\section{References}

1 Shek CC, Swaminathan R. Errors due to heparin in the estimation of plasma sodium and potassium concentrations. Intensive Care Med 1985;11:309-11.

2 Mann SW, Green A. Interference from heparin in commercial heparinised tubes in the measurement of plasma sodium by ion selective electrode: a note of caution. Ann Clin Biochem 1986;23:355-6.

3 Widdowson G. Determination of $\mathrm{pH}, \mathrm{pCO}_{2}$, $\mathrm{pO}_{2}$, sodium and potassium in the same whole blood sample. Ann Clin Biochem 1987; 24:641.

\section{Book reviews}

1988 Year Book of Pathology and Clinical Pathology. Ed. KM Brinkhous. (Pp 423; £35.50.) Wolfe Medical Publications. 1988. ISBN 0-8151-1243-2.

To be honest this is the first time that I have read a Year Book of Pathology. It is an update of the field produced by reviewing refereed and review articles in 79 journals, 67 of which are North American. The book takes the form of 368 pages of abstracts of original and review papers with selected illustrations, accompanied by introductory or summarising editorial comments.

In the main it is an interesting exercise. The editors from the University of North Carolina at Chapel Hill give a fair commentary, although I do not understand how the concept that liposarcomas of the breast are examples of metaplastic breast carcinomas arose, and the abstracts themselves are easily assimilable. My only criticism is the lack of a general review of the events in the period 1986 to mid 1987 which is the year covered by this book.

JD DAVIES

\section{Notices}

\section{Association of Clinical Pathologists}

\section{JUNIOR MEMBERSHIP}

Junior Membership of the Association of Clinical Pathologists is available to trainees in all branches of pathology for up to six years or until they attain consultant status. The annual subscription is $£ 18$, which may be claimed against tax.

All Junior Members receive monthly copies of the Journal of Clinical Pathology. Other benefits include membership of the Junior Members' Group and a regular junior members' newsletter, the ACP Newsletter, and all the documents regularly sent to full members of the Association. These include the twice yearly summary of pathology courses included in the ACP Postgraduate Education Programme.

For Junior Membership apply to: Dr JD Davies, Education Secretary, University Department of Pathology, Bristol Royal Infirmary, Bristol BS2 8HW.

\section{ACP Locum Bureau}

The Association of Clinical Pathologists runs a locum bureau for consultant pathologists.

Applicants with the MRC Path who would like to do locums and anyone requiring a locum should contact $\mathrm{Dr}$ DH Orrell, Department of Pathology, Royal Lancaster Infirmary, Ashton Road, Lancaster LAl 4RP. 